\title{
Perspectives of older adults on co-management of low back pain by doctors of chiropractic and family medicine physicians: a focus group study
}

Kevin J Lyons ${ }^{1}$, Stacie A Salsbury² ${ }^{*}$, Maria A Hondras ${ }^{2,3}$, Mark E Jones ${ }^{4}$, Andrew A Andresen ${ }^{4}$ and Christine M Goertz ${ }^{2}$

\begin{abstract}
Background: While older adults may seek care for low back pain (LBP) from both medical doctors (MDs) and doctors of chiropractic (DCs), co-management between these providers is uncommon. The purposes of this study were to describe the preferences of older adults for LBP co-management by MDs and DCs and to identify their concerns for receiving care under such a treatment model.

Methods: We conducted 10 focus groups with 48 older adults who received LBP care in the past year. Interviews explored participants' care seeking experiences, co-management preferences, and perceived challenges to successful implementation of a MD-DC co-management model. We analyzed the qualitative data using thematic content analysis.

Results: Older adults considered LBP co-management by MDs and DCs a positive approach as the professions have complementary strengths. Participants wanted providers who worked in a co-management model to talk openly and honestly about LBP, offer clear and consistent recommendations about treatment, and provide individualized care. Facilitators of MD-DC co-management included collegial relationships between providers, arrangements between doctors to support interdisciplinary referral, computer systems that allowed exchange of health information between clinics, and practice settings where providers worked in one location. Perceived barriers to the co-management of LBP included the financial costs associated with receiving care from multiple providers concurrently, duplication of tests or imaging, scheduling and transportation problems, and potential side effects of medication and chiropractic care. A few participants expressed concern that some providers would not support a patient-preferred co-managed care model.
\end{abstract}

Conclusions: Older adults are interested in receiving LBP treatment co-managed by MDs and DCs. Older adults considered patient-centered communication, collegial interdisciplinary interactions between these providers, and administrative supports such as scheduling systems and health record sharing as key components for successful LBP co-management.

Keywords: Older adults, Low back pain, Health services for the aged, Interprofessional relations, Chiropractic, Family medicine, Musculoskeletal disorders, Complementary/alternative medicine, Patient preferences, Qualitative research

\footnotetext{
* Correspondence: stacie.salsbury@palmer.edu

${ }^{2}$ Palmer Center for Chiropractic Research, Palmer College of Chiropractic, Davenport, IA, USA

Full list of author information is available at the end of the article
} 


\section{Background}

Low back pain (LBP) is a leading cause of disability and disease burden [1,2]. People age 65 years and older report a $25 \%$ monthly LBP prevalence rate $[3,4]$ with recurrent or debilitating LBP common in older populations [4-6]. Chronic LBP is linked to difficulties with activities of daily living (ADLs) $[7,8]$, depression $[4,7,9,10]$, sleep problems $[7,9]$, and decreased performance on physical function $[7,11]$ and neuropsychological tests [11]. An estimated $2.3 \%$ of annual physician visits in the U.S. are for LBP [3]. Persons with LBP and other spine conditions have increased healthcare expenditures for medications, spinal imaging, injections and surgery [3,4,9,12-14]. Medicare charges among older adults with back disorders have demonstrated significant increases for patient visits, imaging and spinal injections [12,15] without translation to better health outcomes for LBP patients [13-15].

Patients with unresolved pain may pair conventional healthcare with complementary and alternative medicine (CAM) [16-19]. Chiropractic is among the most widely used CAM therapies [16,17,20,21], including by older adults [22-26]. Patients who use medical care and chiropractic together believe the combination helps their condition more than either alone [21]. And yet, co-occurring medical and chiropractic care is uncommon among older patients, ranging from 5-11\% [23] to 33\% [27]. Medical doctors (MDs) and doctors of chiropractic (DCs) make few formal referrals to each other and rarely share health records, suggesting little care coordination between these providers [28-30]. While patients of all ages might benefit from improved co-management of their pain and other medical conditions [31-33], interprofessional collaboration between healthcare providers is particularly important for older adults due to the high rates of chronic disease, multimorbidity and disability [32,34-36], polypharmacy $[37,38]$, and healthcare received from multiple providers [39] in this patient population.

The purpose of this focus group study was to explore the perspectives of older adults toward LBP collaborative care by MDs and DCs. Researchers have conducted focus groups to understand patients' LBP experiences $[40,41]$ and primary care preferences $[42,43]$ and to design interventions for musculoskeletal disease [44-47]. However, researchers have not explored the patient perspective on LBP collaborative care. In this paper, we describe older adults' LBP healthcare seeking experiences, expectations for collaborative care provided by family medicine MDs and DCs, and insights into implementation barriers and facilitators. We incorporated the recommendations from these focus groups into the design of an interdisciplinary model and training plan for DCs and MDs providing co-managed LBP care to older people that was subsequently tested in a pragmatic randomized controlled trial [48].

\section{Methods}

Genesis Health System and Palmer College of Chiropractic institutional review boards provided ethics approval for this study. Focus group methodology allowed the researchers to gather a diverse range of perceptions of older adults who shared the experience of LBP through structured, moderated group discussions [49]. As we could identify no previous studies assessing patient preferences for LBP co-management by MDs and DCs, we could not anticipate which topics might be most important for older adults with this condition. We selected focus groups as a method that would allow for a dynamic data collection process in which group members might immediately discuss new topics introduced by fellow participants while statements offered by one individual might trigger the recollections of other members. We modified standard focus group techniques for use with older adults by using smaller groups and shorter time periods for data collection [50].

We recruited participants by letter from patient lists at a family medicine clinic and chiropractic academic health center and through flyers at two senior centers (SC) and three senior housing (SH) sites. Communitydwelling adults who were 65 years or older and selfreported LBP in the past year were eligible. Participants read and spoke English, heard well enough to join a discussion, and were willing to talk about LBP in a group. Participants provided written consent and completed a demographic survey. Sessions were held in conference rooms and lasted about one hour. Participants received a small gift and snacks for their contributions, but received no monetary compensation.

Table 1 provides the key focus group questions. An interdisciplinary steering committee developed the interview based on a literature review, discussions, and a theory of integrative medicine [51]. The lead author (KJL) facilitated most sessions while assistant moderators (SAS, $\mathrm{MAH}$ ) documented the interview process in fieldnotes and asked follow-up questions. During the introduction to each session, the moderators instructed participants on the aims and methods of focus groups. The moderators emphasized that participants need not agree with one another, that diverse perspectives on LBP care were welcomed, and that the goal of the discussion was not to achieve consensus on the topics under discussion, but, rather, to generate new information based on the participants' own experiences. The moderating team guided the interviews back to the main topic of discussion when irrelevant subjects arose or when a single group member dominated the conversation. The lead moderators also took care to ask the group if they had similar experiences, probed for differing opinions and invited quieter group members to offer their own perspectives to the conversation. Overall, the groups listened intently to the discussions, did not appear hesitant to 


\section{Table 1 Focus group questions}

\begin{tabular}{ll}
\hline LBP healthcare & Which healthcare providers have you seen for \\
seeking & your back condition? \\
& What do you expect a medical doctor to do for \\
& your back condition? \\
& What do you expect a doctor of chiropractic to \\
do for your back condition? & Has your medical doctor or doctor of \\
Referral experiences & chiropractic ever recommended that you see \\
& another health care provider for treatment for \\
& your back? \\
& Have you ever asked your medical doctor/ \\
doctor of chiropractic to refer you to another & health care provider for your back problems? \\
Co-management & What made/might make you decide to seek \\
experiences & treatment from more than one health care \\
provider for your back pain? & Would you mention it to your medical doctor/ \\
doctor of chiropractic if you were also seeing \\
another health care provider for your back \\
problem? Why or why not? \\
Do you think having a medical doctor and a \\
doctor of chiropractic treating your back \\
condition as a team would be helpful? Why or \\
why not? \\
What concerns would you have about seeing a \\
both medical doctor and a doctor of \\
chiropractic for this condition? \\
What could a medical doctor and a doctor of \\
chiropractic do to make it easier for you to see \\
them both for your back problem? \\
facilitators
\end{tabular}

discuss conflicting opinions, and offered supportive comments to participants who expressed emotional concerns. The moderating team presented an oral overview of key themes discussed at the end of the session to confirm initial session findings with participants [52]. Participants then added to or clarified points of the discussion. The moderating team debriefed after each session to identify key topics and format changes to elicit feedback from subsequent groups on emerging themes. Focus group sessions continued until thematic saturation was reached [52,53]. A transcriptionist transcribed the digitally-recorded sessions verbatim that an assistant moderator had compared to the recordings to establish accuracy [53].

Transcriptions were analyzed using content analysis [54]. The lead author (KJL), a social scientist with expertise in interprofessional collaboration, summarized the themes for each focus group and the overall set of groups [49]. The assistant moderators are a gerontological nurse with experience in interdisciplinary teams and qualitative methods (SAS) and a doctor of chiropractic with expertise in LBP in older adults (MAH). The assistant moderators completed a peer review process to affirm the dependability of the initial coding by reading the transcripts and group summaries independently, confirming and expanding the thematic codebook, and classifying themes into discrete domains [53,54]. We organized our analysis at the group level, rather than at the level of the individual. The analytic team organized the themes into data tables and identified which groups discussed each of the themes to identify similarities and differences in the topics generated in discussion across the four different settings from which we recruited participants. Data tables include a checkmark whenever a group discussed a topic. In some cases, many participants may have discussed a topic, while in others only one participant may have introduced an idea. In our results, we use the terms 'most' or 'many' when the majority of participants or the focus groups discussed a particular theme, 'some' when half of the groups identified a topic, and 'few' when themes were discussed by one or two participants in less than half of the groups.

\section{Results}

\section{Participant and group characteristics}

We conducted 10 focus groups between May 2010 and November 2011, with sessions composed of 2 to 10 participants. The sample included 48 participants (10 males and 38 females) whose mean age (SD) was 75.2 (8.0) years. Table 2 presents participant characteristics. Five groups were composed of mixed genders, while one group of family medicine patients, one senior housing group, and two senior center groups had female participants only and one chiropractic patient group had male participants only. Participants in the three senior housing groups differed from the other groups in that few owned their own cars for transportation. The chiropractic patient groups more often spoke of their personal histories of receiving chiropractic care from DCs at this particular clinic compared to members of the other focus groups. Many participants in the senior housing and senior center groups were acquaintances of one another, while the participants in the patient groups were meeting for the first time. Nonetheless, all sessions were characterized by lively discussions regarding these elders' experiences receiving care for LBP. While group members turned to the moderator with their answers early in the discussions, by midway through the sessions the participants spoke directly to one another, nodded or shook their heads in response, and offered supportive or countering opinions.

\section{Back pain causes and consequences}

Participants reported many LBP causes including traumatic injuries from motor vehicle crashes, war wounds, occupational injuries, lifting, pregnancy, domestic violence, or falls. Participants also identified anatomic or physiologic causes including pinched nerves, collapsed 
Table 2 Participant characteristics $(\mathrm{N}=48)$

\begin{tabular}{|c|c|}
\hline Characteristic & \\
\hline Age, mean (SD) & $75.2(8.0)$ \\
\hline Female, \% & 77 \\
\hline Ethnicity, Hispanic \% & 4 \\
\hline Race, white \% & 96 \\
\hline \multicolumn{2}{|l|}{ Marital status, $\%$} \\
\hline Married or living with significant other & 44 \\
\hline Widowed & 40 \\
\hline Divorced or separated & 15 \\
\hline Never married & 2 \\
\hline \multicolumn{2}{|l|}{ Education, \% } \\
\hline Some grade school or high school & 17 \\
\hline High school graduate & 35 \\
\hline Some college or training program & 29 \\
\hline College graduate & 18 \\
\hline \multicolumn{2}{|l|}{ Employment, \% } \\
\hline Retired & 85 \\
\hline Employed & 15 \\
\hline \multicolumn{2}{|l|}{ Overall health, \% } \\
\hline Excellent to very good & 27 \\
\hline Good & 35 \\
\hline Fair & 29 \\
\hline Poor & 6 \\
\hline $\begin{array}{l}\text { Overall pain in past } 24 \text { hours (0-10 NRS), } \\
\text { mean (SD), range }\end{array}$ & $4.7(2.5)$, range $0-9$ \\
\hline $\begin{array}{l}\text { Back pain in past } 24 \text { hours (0-10 NRS), } \\
\text { mean (SD), range }\end{array}$ & $4.2(2.4)$, range $0-9$ \\
\hline \multicolumn{2}{|l|}{ Healthcare providers seen for back pain, $\%$} \\
\hline Doctor of chiropractic & 69 \\
\hline Medical doctor & 60 \\
\hline Physical therapist & 38 \\
\hline Doctor of osteopathy & 17 \\
\hline Massage therapist & 8 \\
\hline
\end{tabular}

SD Standard deviation.

NRS Numerical Rating Scale.

vertebrae, degenerative discs or spinal stenosis attributed to aging, heredity or poor posture. Conditions such as arthritis, knee or hip replacements, or diabetes often accompanied LBP. Onset varied with some participants reporting LBP for 30 to 50 years, while for others LBP coincided with retirement. Intensity ranged from an annoyance to debilitating. Most respondents functioned with LBP, but many modified ADLs to lessen or prevent pain. Participants were cautious during lifting, driving, vacuuming, mowing, recreation, and with sudden movements.

\section{Healthcare seeking experiences}

When these older adults experienced LBP, they attempted to self-manage the pain with over-the-counter medications (e.g., acetaminophen, ibuprofen, aspirin, naproxen, creams), heat or cold applications, position changes, and self-massage. Exercise sometimes triggered LBP, but also was a preventive or relieving strategy and included walking, swimming, stretching and yoga. Participants sought professional care when LBP became burdensome with pain relief as the primary motivator (Table 3 ). These older adults chose treatment from two types of primary care providers: family or internal medicine physicians and doctors of chiropractic. Participants also received care from physical therapists, neurologists, massage therapists, and orthopedists. Most participants avoided injections or surgery stating they would rather "live with pain."

The consensus across groups was that older adults who saw a medical doctor for LBP might receive a prescription, self-care recommendations, or referral to specialists or physical therapy (Table 3). As one SC participant said: "Usually they'll take some $\mathrm{x}$-rays to see what's going on. Then what they probably do is give you some pills to mask the pain." Others felt medical care addressed her back problems very well: "Last one I had when my back hurt, they gave me some medicine...it got rid of it [the pain] right now."

Participants across groups considered chiropractic a primary, not complementary, LBP treatment. Participants said DCs offered many modalities, but expected chiropractors to provide "hands-on" treatments or spinal manipulation to deal with the cause of the pain (Table 3). One participant noted, "You expect them to give you adjustments to...not only to loosen you up, but maybe take the pain out of your spine or out of your joints. A regular doctor will not give you an adjustment. He can only give you medication." Others, like this SC member, reported DCs also talked with them at length about their condition: "Chiropractors, they spend time with you, discussing what's going on and they don't rush you through."

\section{LBP Co-management facilitators}

When presented with the idea, most participants believed collaboration by a MD-DC team could be a positive treatment approach to LBP (Table 4). Participants noted DCs and MDs did sometimes refer patients: "My chiropractor told me go to the medical doctor to make sure there's nothing else going on." While many participants sought LBP treatment from multiple providers, none had received concurrent care from a MD and DC who communicated about their diagnosis and plan of care. As one SC participant said, "I like the idea that they work together, that they communicate, that they even discuss what the plan should be." Several elders, 
Table 3 Expectations for medical and chiropractic treatment of low back pain

\begin{tabular}{|c|c|c|c|c|c|c|c|c|c|c|}
\hline \multirow{3}{*}{ Medical treatments for LBP } & \multicolumn{2}{|c|}{ MD clinic $(n=8)$} & \multicolumn{2}{|c|}{ DC clinic $(n=6)$} & \multicolumn{3}{|c|}{ Senior center $(n=12)$} & \multicolumn{3}{|c|}{ Senior housing $(n=22)$} \\
\hline & $M$ & $M$ & D1 & D & $\mathrm{C}$ & $\mathrm{C}$ & $\mathrm{C}$ & $\mathrm{H}$ & $\mathbf{H}$ & $\mathrm{H}$ \\
\hline & 1 & 2 & 1 & 2 & 1 & 2 & 3 & 1 & 2 & 3 \\
\hline Pain relief expected & $\checkmark$ & $\checkmark$ & $\checkmark$ & & $\checkmark$ & $\checkmark$ & $\checkmark$ & $\checkmark$ & $\checkmark$ & $\checkmark$ \\
\hline Prescription medicine suggested & $\checkmark$ & $\checkmark$ & $\checkmark$ & $\checkmark$ & $\checkmark$ & $\checkmark$ & $\checkmark$ & $\checkmark$ & $\checkmark$ & $\checkmark$ \\
\hline X-ray or diagnostic tests performed & $\checkmark$ & $\checkmark$ & $\checkmark$ & $\checkmark$ & $\checkmark$ & $\checkmark$ & $\checkmark$ & $\checkmark$ & $\checkmark$ & $\checkmark$ \\
\hline Self-care/exercise recommendations & $\checkmark$ & $\checkmark$ & $\checkmark$ & $\checkmark$ & $\checkmark$ & $\checkmark$ & $\checkmark$ & & $\checkmark$ & $\checkmark$ \\
\hline Referral to specialist or pain clinic & $\checkmark$ & & $\checkmark$ & $\checkmark$ & $\checkmark$ & $\checkmark$ & $\checkmark$ & $\checkmark$ & $\checkmark$ & $\checkmark$ \\
\hline Surgery or injection recommendation & $\checkmark$ & & & & $\checkmark$ & $\checkmark$ & $\checkmark$ & $\checkmark$ & $\checkmark$ & $\checkmark$ \\
\hline Referral to doctor of chiropractic & $\checkmark$ & $\checkmark$ & & $\checkmark$ & & & $\checkmark$ & $\checkmark$ & $\checkmark$ & \\
\hline \multirow[t]{2}{*}{ Chiropractic treatments for LBP } & $M$ & $M$ & D & D & $\mathrm{C}$ & $\mathrm{C}$ & $\mathrm{C}$ & $\mathrm{H}$ & $\mathrm{H}$ & $\mathrm{H}$ \\
\hline & 1 & 2 & 1 & 2 & 1 & 2 & 3 & 1 & 2 & 3 \\
\hline Pain relief expected & $\checkmark$ & $\checkmark$ & $\checkmark$ & $\checkmark$ & & $\checkmark$ & $\checkmark$ & $\checkmark$ & $\checkmark$ & $\checkmark$ \\
\hline Hands-on treatment/adjustment given & $\checkmark$ & $\checkmark$ & $\checkmark$ & $\checkmark$ & & $\checkmark$ & $\checkmark$ & $\checkmark$ & $\checkmark$ & $\checkmark$ \\
\hline Treatment of the cause of LBP problem & $\checkmark$ & $\checkmark$ & $\checkmark$ & $\checkmark$ & & $\checkmark$ & $\checkmark$ & $\checkmark$ & $\checkmark$ & $\checkmark$ \\
\hline Loosen up joints/maintain mobility & $\checkmark$ & $\checkmark$ & $\checkmark$ & $\checkmark$ & & $\checkmark$ & $\checkmark$ & $\checkmark$ & & \\
\hline Other modalities (TENS, instruments) & $\checkmark$ & $\checkmark$ & $\checkmark$ & $\checkmark$ & $\checkmark$ & & $\checkmark$ & $\checkmark$ & $\checkmark$ & $\checkmark$ \\
\hline X-ray or diagnostic tests performed & & & & $\checkmark$ & & $\checkmark$ & $\checkmark$ & $\checkmark$ & $\checkmark$ & $\checkmark$ \\
\hline Chiropractic maintenance care helps & $\checkmark$ & $\checkmark$ & $\checkmark$ & $\checkmark$ & & $\checkmark$ & $\checkmark$ & $\checkmark$ & $\checkmark$ & $\checkmark$ \\
\hline Adjustment provides short-term relief & $\checkmark$ & $\checkmark$ & & $\checkmark$ & & $\checkmark$ & $\checkmark$ & $\checkmark$ & $\checkmark$ & \\
\hline Treatment approaches vary by DC & $\checkmark$ & $\checkmark$ & $\checkmark$ & & & $\checkmark$ & & $\checkmark$ & $\checkmark$ & $\checkmark$ \\
\hline Referral to medical doctor & $\checkmark$ & $\checkmark$ & & & & & & $\checkmark$ & $\checkmark$ & $\checkmark$ \\
\hline Self-care/exercise recommendations & & $\checkmark$ & & $\checkmark$ & & $\checkmark$ & $\checkmark$ & & & \\
\hline
\end{tabular}

$\mathrm{MD}=$ Medical Doctor.

$\mathrm{DC}=$ Doctor of Chiropractic.

$\mathrm{LBP}=$ Low back pain.

M\# = Medical clinic focus group 1 or 2 .

$\mathrm{D \#}=$ Chiropractic clinic focus group 1 or 2 .

C\# = Senior center focus group 1,2 or 3 .

$\mathrm{H} \#=$ Senior housing focus group 1,2 or 3 .

TENS = Transcutaneous electrical nerve stimulation

including this $\mathrm{SH}$ participant, questioned why comanagement between these providers was not a current standard of practice: "They consult with other medical doctors, so if they consulted with your chiropractor too, in the same context, I think it would benefit everybody in the long run."

Participants emphasized that in a co-management situation doctors should respect one another as colleagues. Most focus groups had a perception of strained professional relationships between MDs and DCs in the past, but many felt this situation has changed for the better over their lifetimes. Many participants also stated the doctors should work physically close to one another for optimal collaboration: "If they had an office together, and would discuss the plan, it would be a good thing for me, because one is doing this [chiropractic], and one is medicine."

One SH participant suggested collaborating doctors should at least communicate by telephone: "I wouldn't mind if they talked to each other on the phone and discussed my case." Participants also recommended health record sharing. Few had privacy concerns for such interdisciplinary communication, especially if the burden of completing multiple forms or transferring records was minimized. Another SH participant said: "If they shared the medical chart that they have on you with the chiropractor, with the charts he has on you, between the two of them they could resolve a lot of things without the medication if they compared notes." A medical patient concurred: "I think information sharing is the main thing."

\section{LBP Co-management concerns}

While generally agreeing that MD-DC collaboration was a good idea, some participants wondered about its benefit or efficacy, particularly when dissatisfied from previous experiences receiving care from either provider (Table 4). Some participants were concerned about overlap in testing or treatment. As a medical clinic participant said, 
Table 4 Older adult perceptions of potential facilitators and barriers of low back pain co-management by MDs and DCs

\begin{tabular}{|c|c|c|c|c|c|c|c|c|c|c|}
\hline \multirow{3}{*}{ LBP Co-management facilitators } & \multicolumn{2}{|c|}{ MD clinic } & \multicolumn{2}{|c|}{ DC clinic } & \multicolumn{3}{|c|}{ Senior center } & \multicolumn{3}{|c|}{ Senior housing } \\
\hline & M & M & D & D & $\mathrm{C}$ & $\mathrm{C}$ & $\mathrm{C}$ & $\mathbf{H}$ & $\mathbf{H}$ & $\mathbf{H}$ \\
\hline & 1 & 2 & 1 & 2 & 1 & 2 & 3 & 1 & 2 & 3 \\
\hline Co-management would benefit LBP patient & $\checkmark$ & $\checkmark$ & $\checkmark$ & $\checkmark$ & $\checkmark$ & $\checkmark$ & $\checkmark$ & & $\checkmark$ & $\checkmark$ \\
\hline Collegial approach needed for LBP care & $\checkmark$ & $\checkmark$ & $\checkmark$ & $\checkmark$ & $\checkmark$ & $\checkmark$ & $\checkmark$ & $\checkmark$ & $\checkmark$ & $\checkmark$ \\
\hline $\begin{array}{l}\text { Historically strained relations between MDs and DCs } \\
\text { has improved over time }\end{array}$ & $\checkmark$ & $\checkmark$ & $\checkmark$ & $\checkmark$ & & $\checkmark$ & $\checkmark$ & $\checkmark$ & $\checkmark$ & $\checkmark$ \\
\hline $\begin{array}{l}\text { Referrals/consultations/phone calls between } \mathrm{MD} \text { and } \\
\text { DC needed for co-management }\end{array}$ & $\checkmark$ & $\checkmark$ & $\checkmark$ & $\checkmark$ & & $\checkmark$ & $\checkmark$ & $\checkmark$ & $\checkmark$ & $\checkmark$ \\
\hline Coordinated LBP treatment plan & $\checkmark$ & $\checkmark$ & $\checkmark$ & $\checkmark$ & $\checkmark$ & $\checkmark$ & $\checkmark$ & & $\checkmark$ & $\checkmark$ \\
\hline Health record/X-ray sharing required & $\checkmark$ & $\checkmark$ & & $\checkmark$ & $\checkmark$ & $\checkmark$ & $\checkmark$ & $\checkmark$ & $\checkmark$ & $\checkmark$ \\
\hline Offices located together or nearby & & $\checkmark$ & $\checkmark$ & & $\checkmark$ & & $\checkmark$ & $\checkmark$ & & \\
\hline Individualized care for LBP & $\checkmark$ & $\checkmark$ & & & & $\checkmark$ & $\checkmark$ & $\checkmark$ & $\checkmark$ & \\
\hline \multirow[t]{2}{*}{ LBP Co-management barriers/concerns } & $M$ & M & D & D & $C$ & $C$ & $C$ & $\mathrm{H}$ & $\mathrm{H}$ & $\mathrm{H}$ \\
\hline & 1 & 2 & 1 & 2 & 1 & 2 & 3 & 1 & 2 & 3 \\
\hline $\begin{array}{l}\text { Medication: do not want to use any medicine, side effects, } \\
\text { no improvement, narcotic addiction, masking pain }\end{array}$ & $\checkmark$ & $\checkmark$ & $\checkmark$ & $\checkmark$ & $\checkmark$ & $\checkmark$ & $\checkmark$ & $\checkmark$ & $\checkmark$ & $\checkmark$ \\
\hline $\begin{array}{l}\text { Financial costs or insurance issues from receiving care from } \\
2 \text { or more doctors }\end{array}$ & $\checkmark$ & $\checkmark$ & $\checkmark$ & & $\checkmark$ & $\checkmark$ & $\checkmark$ & $\checkmark$ & $\checkmark$ & $\checkmark$ \\
\hline Providers may not support a co-management approach to LBP care & $\checkmark$ & $\checkmark$ & $\checkmark$ & & $\checkmark$ & $\checkmark$ & $\checkmark$ & $\checkmark$ & $\checkmark$ & $\checkmark$ \\
\hline $\begin{array}{l}\text { Chiropractic: Side effects, providers who do not treat a condition, } \\
\text { no improvement }\end{array}$ & $\checkmark$ & $\checkmark$ & $\checkmark$ & & & $\checkmark$ & $\checkmark$ & $\checkmark$ & $\checkmark$ & $\checkmark$ \\
\hline Receiving care from multiple doctors & $\checkmark$ & & & & $\checkmark$ & $\checkmark$ & $\checkmark$ & $\checkmark$ & $\checkmark$ & $\checkmark$ \\
\hline Duplicate/unneeded tests/treatments & $\checkmark$ & & & & $\checkmark$ & $\checkmark$ & $\checkmark$ & $\checkmark$ & $\checkmark$ & \\
\hline Conflicting information or treatments & $\checkmark$ & & & & $\checkmark$ & $\checkmark$ & $\checkmark$ & $\checkmark$ & $\checkmark$ & \\
\hline Scheduling and transportation concerns & & & & & $\checkmark$ & $\checkmark$ & $\checkmark$ & $\checkmark$ & $\checkmark$ & $\checkmark$ \\
\hline $\begin{array}{l}\text { Questionable benefit of either medical, chiropractic, or co-management } \\
\text { based on previous LBP treatment experience }\end{array}$ & & & & & $\checkmark$ & $\checkmark$ & $\checkmark$ & $\checkmark$ & $\checkmark$ & $\checkmark$ \\
\hline
\end{tabular}

$\mathrm{MD}=$ Medical Doctor.

$\mathrm{DC}=$ Doctor of Chiropractic.

LBP $=$ Low back pain.

$\mathrm{M \#}=$ Medical clinic focus group 1 or 2

$\mathrm{D \#}=$ Chiropractic clinic focus group 1 or 2 .

$\mathrm{C \#}=$ Senior center focus group 1, 2 or 3 .

$\mathrm{H} \#=$ Senior housing focus group 1,2 or 3 .

"You go to a medical doctor and he takes x-rays or MRIs...and then you go to a chiropractor and he takes $\mathrm{x}$ rays. I think you can overdo that process...but if they worked together and used the same tests... that helps."

Most participants were concerned about prescription medicine use in any collaborative model. Many older adults, like this $\mathrm{SH}$ participant, reported they did not use their pain medicine: "I don't take half the prescriptions. I tear them up...I won't try it." Some feared addiction and only took medicine, especially opioids, when the pain became "unbearable." Still others reported medication side effects: "I could not take it, because it was too strong, and I was drowsy all the time." Similarly, some participants noted chiropractic adjustments did not relieve their LBP for several treatments, provided short-term relief or produced side effects, such as muscle soreness.
The logistical aspects of LBP collaborative care also were concerns. Participants stated they could not afford the financial expense, including insurance co-pays and out-of-pocket costs, associated with seeing different specialists for multiple co-morbidities. One $\mathrm{SH}$ participant said: "They could send me to all the specialists they want, but I don't have the money to pay for it." Older adults who had mobility issues, used public transportation, or lived in senior housing would need special travel arrangements. This SH participant said, "The time involved... you go to one doctor and then you're going to another one that's across town...my friend's taken me to all of my appointments." Scheduling was problematic, as a SC participant noted: "My biggest problem is getting through the office secretary for a time. "We can see you in four, five days. Otherwise go to the emergency room.' 
What good is that, because they will say, "Well, go to your family doctor.' You get the runaround."

Participants also thought some providers might not engage in collaborative practice, even if the patient was interested. As a SC participant said, "I would not like my physician to say, 'Do not seek chiropractic treatment.' And I would not like my chiro to say, 'You don't need any other help. I can do everything for you.' I would like them to work together."

\section{Patient-centered communication}

Patient-centered communication was essential for LBP collaborative care, or for any interaction between a patient and healthcare provider (Table 5). Participants across groups reported professionals from many disciplines responded to LBP concerns with statements such as, "You're fine...for your age." Others were frustrated when providers prioritized other health conditions over LBP: "I go to [doctor] and his only concern is my diabetes. I tried to talk to him about back pain...It's ten minutes in and you're gone, which is too bad."

Some older adults, like this SC participant, felt doctors treated them as a number rather than as a person: "There's few doctors nowadays that actually sit and listen to you, and haven't made up their mind what they're to do for you ahead of time." Participants preferred providers who treated them with respect, cared for their individual needs, and recognized the patient as the expert. As a SC participant stated: "I want respect shown to the patient. There isn't anybody that knows their body any better than that person and for a doctor to, or a nurse or anyone to say, 'You shouldn't be having that kind of pain'...You need to teach, treat each separately."

Some older adults felt providers did not offer enough information about their LBP. Most, like this SC participant, wanted honest communication regarding their LBP condition, including its diagnosis, prognosis and treatment: "When you tell them you have an issue, things could be changing, but they just say, 'Well, your old back is hurting you. Let's try this medicine.' I would like to know what changes are going on, and what's going on, and why." These older adults also thought patients should be accountable when talking about their treatment from other providers. One SH participant said, "I think you definitely have to because that way it's a group effort to get you better." Others, like this SC participant, noted the importance of such transparency on health history forms: "They knew I was doing that because you fill out forms when you go in the office, 'Are you being seen by...' Yes, yes, yes, yes, so they already know what I was doing."

Participants across groups proffered that collaborating doctors should provide consistent recommendations. As this SC participant noted: "I was just thinking you go to your chiro and he tells you one thing. You go to your doctor and he says, 'Oh, I don't think you should be doing that.' What if they worked together? I think that would be really good." When asked how to reconcile divergent recommendations, many participants said disagreements about the plan of care demonstrated the

Table 5 Older adults' recommendations regarding patient-centered communication for LBP co-management by MDs and DCs

\begin{tabular}{|c|c|c|c|c|c|c|c|c|c|c|}
\hline & \multicolumn{2}{|c|}{ MD clinic } & \multicolumn{2}{|c|}{ DC clinic } & \multicolumn{3}{|c|}{ Senior center } & \multicolumn{3}{|c|}{ Senior housing } \\
\hline & $M$ & $\bar{M}$ & D & $\bar{D}$ & $\mathrm{C}$ & $\mathrm{C}$ & $\mathrm{C}$ & $\mathrm{H}$ & $\mathbf{H}$ & $\mathbf{H}$ \\
\hline & 1 & 2 & 1 & 2 & 1 & 2 & 3 & 1 & 2 & 3 \\
\hline $\begin{array}{l}\text { Providers should use respectful, honest communication between each other } \\
\text { and with patients }\end{array}$ & & $\checkmark$ & $\checkmark$ & $\checkmark$ & $\checkmark$ & $\checkmark$ & $\checkmark$ & $\checkmark$ & $\checkmark$ & $\checkmark$ \\
\hline Provider must listen to the patient & $\checkmark$ & $\checkmark$ & & $\checkmark$ & $\checkmark$ & $\checkmark$ & $\checkmark$ & $\checkmark$ & $\checkmark$ & $\checkmark$ \\
\hline Patient must let doctors know they are seeing other providers for LBP & $\checkmark$ & $\checkmark$ & $\checkmark$ & $\checkmark$ & $\checkmark$ & $\checkmark$ & $\checkmark$ & $\checkmark$ & $\checkmark$ & \\
\hline Providers should explain condition, diagnosis, treatment and prognosis & & $\checkmark$ & $\checkmark$ & & $\checkmark$ & $\checkmark$ & $\checkmark$ & $\checkmark$ & $\checkmark$ & $\checkmark$ \\
\hline Patients should use their own judgment about any advice for LBP & & $\checkmark$ & $\checkmark$ & $\checkmark$ & & $\checkmark$ & & $\checkmark$ & $\checkmark$ & $\checkmark$ \\
\hline Providers should spend more time with patient & & & & $\checkmark$ & $\checkmark$ & $\checkmark$ & $\checkmark$ & $\checkmark$ & $\checkmark$ & $\checkmark$ \\
\hline Providers should not blame LBP on the older adults' health condition or age & & $\checkmark$ & $\checkmark$ & & & $\checkmark$ & $\checkmark$ & $\checkmark$ & $\checkmark$ & $\checkmark$ \\
\hline Providers should discuss pain openly with their patients & & & & & $\checkmark$ & $\checkmark$ & $\checkmark$ & $\checkmark$ & $\checkmark$ & $\checkmark$ \\
\hline MD-DC should resolve disagreements and present unified LBP approach to patient & $\checkmark$ & & & & $\checkmark$ & $\checkmark$ & $\checkmark$ & $\checkmark$ & & \\
\hline If dissatisfied with care, patient should change doctors or get another opinion & $\checkmark$ & $\checkmark$ & $\checkmark$ & & & $\checkmark$ & & $\checkmark$ & $\checkmark$ & $\checkmark$ \\
\hline
\end{tabular}

$\mathrm{MD}=$ Medical Doctor.

$\mathrm{DC}=$ Doctor of Chiropractic.

LBP $=$ Low back pain.

$\mathrm{M \#}=$ Medical clinic focus group 1 or 2 .

$\mathrm{D \#}=$ Chiropractic clinic focus group 1 or 2 .

$\mathrm{C \#}=$ Senior center focus group 1, 2 or 3 .

$\mathrm{H} \#=$ Senior housing focus group 1,2 or 3 . 
providers were not working together. Another participant questioned providers who put the patient in the middle with conflicting recommendations: "They're not communicating with each other...Right? Wouldn't you say that? If they're going to do the complete opposite, then they don't really have any respect for each other. They don't talk about it. How are we supposed to determine who's right, who's wrong?"

Some participants reported that they would resolve this issue by seeking a third opinion, while others stated a disagreement might make them reconsider care from either doctor: "I probably wouldn't go to either one." Most participants would consider both recommendations and use their own judgment to decide on the best approach for their LBP. One SH resident said, "I would evaluate both situations...find something that I could read up on... and make my own decision as to which I'd follow up because I know my body better than any doctor." Another SH participant summed up the benefits of patient-centered communication within the context of MD-DC collaboration: "I would expect them to get to the base of the problem. I think the biggest thing...tell the patient what's going on and what's going through the medical person's mind and...the chiropractor, explain it...that makes a big difference."

\section{Discussion}

While previous research has evaluated collaborative models for primary care $[43,55,56]$, this study is among the first to assess older adults' preferences for LBP comanagement by MDs and DCs in primary care settings. The dynamics of collaboration between healthcare providers may vary widely, as identified by Boon and colleagues [57,58], who have developed a seven model conceptual framework of team-oriented health care delivery. In this study, our participants largely described models of LBP treatment that may be best described as parallel practice with some consultative practice [58]. For example, most participants sought pain relief from both MDs and DCs, but no participant had experienced MDDC collaborative care for LBP in which their providers shared health information or coordinated their care in any way. Nonetheless, our participants considered MDDC collaboration a feasible treatment model. These older adults emphasized honest and respectful communication between health professionals for LBP co-management success. Participants also stressed the importance of providers' direct, honest, and consistent communication with older adults suggesting any co-management model must embrace a patient-centered care approach, a finding that echoes other studies of patient preferences for doctorpatient communication [31,43,44,59-61].

Older adults were interested in talking with doctors about their diagnoses, prognosis and treatment options, as other research in primary care settings has shown $[18,61,62]$. A recent study found the quality of communication between LBP patients and 3 professional subgroups (MD, DC, and physical therapy) were worse the longer the patient had LBP and in older patients [63]. Physicians demonstrate low confidence and knowledge scores toward evaluation and treatment of LBP in elderly people [64]. While comparative studies for DCs are unavailable, chiropractic students are less knowledgeable about primary care, other than musculoskeletal conditions, than medical students [65]. Our findings suggest a MD-DC team approach may fill the knowledge and skill gaps of each provider, as primary care patients desire competent clinicians who know when to seek assistance from other professionals [66]. Intensive training and practice in communication skills may benefit health professionals who work with older adults and patients using CAM $[61,67,68]$. Healthcare providers should develop communication skills that assist patients with LBP to set realistic expectations about their treatment options, understand their potential outcomes, and engage in an active role in their therapeutic process [69].

Barriers to LBP co-management identified by these participants included financial costs, scheduling and transportation issues, and side effects from medication or chiropractic treatment, similar to other studies [42,43,61]. Participants thought some providers would be unwilling to engage in collaborative practice, a finding noted in other studies that have explored combining conventional and complementary approaches to healthcare [42,51]. Participants viewed information sharing between doctors through provider referral, communication by telephone or in shared practice settings, or via computer-mediated health record exchange as an essential facilitator of LBP co-management. Previous studies of interdisciplinary practice by MDs and DCs revealed little concurrent care, referral or record sharing by these providers [23,27-30] suggesting the need for pragmatic co-management models to guide such practice innovations.

Through this focus group study, we improved our model of collaborative care for older adults with back pain and the interprofessional context in which this model was tested [48]. Our results also have implications for clinical practice. These participants were uneasy about pain medicine because of potential side effects, a finding expressed by other primary care and CAM patients in other studies $[18,43,70]$. Some participants refused to take pain medicine and chose to "live with pain". One preliminary study demonstrated structural brain changes in older adults with chronic LBP [71], suggesting elders' decisions to "live with pain" may be detrimental not only to their quality of life $[4,7,9]$ but their cognitive status as well [71]. Health providers who co-manage LBP in older adults should be aware of their 
concerns regarding medication safety, the preferences of many elders for minimal medication use for pain relief, and the need to ascertain whether their patients are using their medications as prescribed.

\section{Study limitations}

This study has limitations. While focus group methodology was used to elicit a range of opinions [49] about LBP collaborative care, participants may not have shared their thoughts or feelings about this topic completely. Selection bias may be present. Our sample may differ from the target population of older adults with back pain given the unique geographic setting of our study. Palmer College of Chiropractic was established as the founding chiropractic college in 1897; subsequently, community awareness of chiropractic as a treatment for LBP is very long-standing. While we are not aware of such statistics, it is reasonable to suggest that more people in the Quad-Cities would have tried both medical and chiropractic care for LBP than would be found in the general population. Thus, the participants in this study may be more open to LBP co-management approaches by MDs and DCs than other LBP patients. We recruited participants from a variety of settings; however, many older adults in this community did not have the opportunity to participate. Older adults who had not sought care from these clinics, resided in long-term care settings or were homebound, did not speak English or attend senior centers, and those closed to co-management were not represented. Several potential participants stated they were not interested in discussing back pain, as they sought to live fully despite occasional discomforts. These seniors suggested future recruitment efforts promote back health. Lastly, our study focused on older adults with LBP. While our findings also may apply to younger and middle-aged adults seeking care for back pain, the unique needs of those working-aged individuals may warrant additional study.

\section{Conclusions}

This focus group study demonstrated an interest among older adults with back pain in co-management models by medical doctors and doctors of chiropractic. Older adults viewed collaboration between these providers as a potentially advantageous approach for back problems. Participants thought the combination of medical treatments and chiropractic adjustments might best achieve their goals for pain relief for low back conditions and improved physical function.

Older adults identified financial costs, scheduling and transportation issues, side effects from medication or chiropractic treatment, duplicate testing, and providers' willingness to engage in collaborative care models as potential barriers to low back pain co-management.
Facilitators of back pain treatment provided jointly by medical doctors and doctors of chiropractic included a collegial approach between providers, referral and consultation relationships, health record sharing, and colocated clinics. Patient-centered communication that included respect for the older adult as the expert in his or her own body, an openness to discussing chronic pain and diagnoses, refraining from blaming back pain on the patient's age, and an individualized approach to treatment were considered key components of LBP collaborative care.

\section{Abbreviations}

ADL: Activities of daily living; CAM: Complementary and alternative medicine; DC: Doctor of chiropractic; LBP: Low back pain; MD: Medical doctor; NRS: Numerical rating scale; SC: Senior center; SD: Standard deviation; SH: Senior housing; TENS: Transcutaneous electrical nerve stimulation.

\section{Competing interests}

The authors declare they have no competing interests.

\section{Authors' contributions}

The study was conceived and the interview designed by $C M G, K J$, SAS, MAH, MEJ, and AAA. SAS, MEJ, AAA, and CMG were involved in participant recruitment. The focus group moderating and data analysis team included $\mathrm{KJ}, \mathrm{SAS}$, and MAH. KJL and SAS drafted the manuscript. MAH, CMG, MEJ, and AAA provided manuscript revisions. All authors read and approved the final manuscript.

\section{Acknowledgments}

The authors thank the focus group participants for sharing their time and insights on the possibilities for collaborative care of back pain. We appreciated the thoughtful comments of steering committee members Drs. Robert Vining, Lisa Killinger, Fredric Wolinsky, and Cynthia Long on the focus group project. We are grateful to Dr. Robert Wallace for his critical reviews of the focus group questions and manuscript. We thank Dr. Paige Morgenthal for her excellent editing skills. We thank Katherine Brasch at Genesis Family Medical Center and Kim Hutchison at the Palmer Academic Health Center for assistance with participant recruitment. We also thank the following Quad-City senior organizations for the use of their facilities and help with recruitment: Generations Area Agency on Aging, the Center for Active Seniors, Inc., Moline Activity Center, Luther Manor, Luther Crest, and Spring Village Apartments. We thank the Palmer Center for Chiropractic Research Office of Data Management and Biostatistics for their assistance with data entry and analysis and the study coordinators from the Palmer Research Clinic for their assistance with the recruitment mailing. This research was funded by the U.S. Health Resources and Services Administration (5R18HP15126, Goertz, PI). The contents of this article are solely the responsibility of the authors and do not necessarily reflect the official views of the sponsoring agency. These findings were presented at the International Research Congress on Integrative Medicine and Health 2012, Portland, Oregon, USA, 15-18 May 2012.

\section{Author details}

${ }^{1}$ Office of Institutional Research, Thomas Jefferson University, Philadelphia, PA, USA. ${ }^{2}$ Palmer Center for Chiropractic Research, Palmer College of Chiropractic, Davenport, IA, USA. ${ }^{3}$ Institute of Sports Science and Clinical Biomechanics, University of Southern Denmark, Odense, Denmark. ${ }^{4}$ Genesis Quad Cities Family Medicine Residency Program, Davenport, IA, USA.

Received: 14 June 2013 Accepted: 11 September 2013

Published: 16 September 2013

\section{References}

1. Vos T, Flaxman AD, Naghavi M, Lozano R, Michaud C, Ezzati M, Shibuya K, Salomon JA, Abdalla S, Aboyans V: Years lived with disability (YLDs) for 1160 sequelae of 289 diseases and injuries 1990-2010: a systematic 
analysis for the Global Burden of Disease Study 2010. Lancet 2012, 380:2163-2196.

2. Murray CJL, Vos T, Lozano R, Naghavi M, Flaxman AD, Michaud C, Ezzati M, Shibuya K, Salomon JA, Abdalla S: Disability-adjusted life years (DALYs) for 291 diseases and injuries in 21 regions, 1990-2010: a systematic analysis for the Global Burden of Disease Study 2010. Lancet 2012, 380:2197-2223.

3. Deyo RA, Mirza SK, Martin BI: Back pain prevalence and visit rates: estimates from U.S. national surveys, 2002. Spine 2006, 31:2724-2727.

4. Docking RE, Fleming J, Brayne C, Zhao J, Macfarlane GJ, Jones GT: Epidemiology of back pain in older adults: prevalence and risk factors for back pain onset. Rheumatology 2011, 50:1645-1653.

5. Dionne CE, Dunn KM, Croft PR: Does back pain prevalence really decrease with increasing age? A systematic review. Age Ageing 2006, 35:229-234.

6. Makris UE, Fraenkel L, Han L, Leo-Summers L, Gill TM: Epidemiology of restricting back pain in community-living older persons. J Amer Geriatr Soc 2011, 59:610-614.

7. Rudy TE, Weiner DK, Lieber SJ, Slaboda J, Boston JR: The impact of chronic low back pain on older adults: a comparative study of patients and controls. Pain 2007, 131:293-301.

8. Hicks GE, Gaines JM, Shardell M, Simonsick EM: Associations of back and leg pain with health status and functional capacity of older adults: findings from the retirement community back pain study. Arthritis Rheum 2008, 59:1306-1313.

9. Gore M, Sadosky A, Stacey BR, Tai KS, Leslie D: The burden of chronic low back pain: clinical comorbidities, treatment patterns, and health care costs in usual care settings. Spine 2012, 37:E668-E677.

10. Reid MC, Williams CS, Concato J, Tinetti ME, Gill TM: Depressive symptoms as a risk factor for disabling back pain in community-dwelling older persons. J Amer Geriatr Soc 2003, 51:1710-1717.

11. Weiner DK, Rudy TE, Morrow L, Slaboda J, Lieber S: The relationship between pain, neuropsychological performance, and physical function in community dwelling older adults with chronic low back pain. Pain Med 2006, 7:60-70

12. Deyo RA, Mirza SK, Martin BI, Kreuter W, Goodman DC, Jarvik JG: Trends, major medical complications, and charges associated with surgery for lumbar spinal stenosis in older adults. JAMA 2010, 303:1259-1265.

13. Martin BI, Deyo RA, Mirza SK, Turner JA, Comstock BA, Hollingworth W, Sullivan SD: Expenditures and health status among adults with back and neck problems. JAMA 2008, 299:656-664.

14. Martin BI, Turner JA, Mirza SK, Lee MJ, Comstock BA, Deyo RA: Trends in health care expenditures, utilization, and health status among US adults with spine problems, 1997-2006. Spine 2009, 34:2077-2084.

15. Weiner DK, Kim YS, Bonino P, Wang T: Low back pain in older adults: are we utilizing healthcare resources wisely? Pain Med 2006, 7:143-150.

16. Barnes PM, Bloom B, Nahin RL: Complementary and alternative medicine use among adults and children: United States. Natl Health Stat Report 2007, 2008:1-23.

17. Wolsko PM, Eisenberg DM, Davis RB, Kessler R, Phillips RS: Patterns and perceptions of care for treatment of back and neck pain: results of a national survey. Spine 2003, 28:292-297.

18. Franzel B, Schwiegershausen $M$, Heusser $P$, Berger B: Individualised medicine from the perspectives of patients using complementary therapies: a meta-ethnography approach. BMC Complement Altern Med 2013, 13:124.

19. Chenot JF, Becker A, Leonhardt C, Keller S, Donner-Banzhoff N, Baum E, Pfingsten M, Hildebrandt J, Basler HD, Kochen M: Use of complementary alternative medicine for low back pain consulting in general practice: a cohort study. BMC Complement Altern Med 2007, 7:42.

20. Sherman K, Cherkin D, Connelly M, Erro J, Savetsky J, Davis R, Eisenberg D: Complementary and alternative medical therapies for chronic low back pain: what treatments are patients willing to try? BMC Complement Altern Med 2004, 4:9.

21. Barnes P, Powell-Griner E, McFann K, Nahin RL: Complementary and alternative medicine use among adults: United States, 2002. Adv Dato 2004, 343:1-19.

22. Wolinsky FD, Liu L, Miller TR, Geweke JF, Cook EA, Greene BR, Wright KB, Chrischilles EA, Pavlik CE, An H, Ohsfeldt RL, Richardson KK, Rosenthal GE, Wallace RB: The use of chiropractors by older adults in the United States. Chiropr Osteopat 2007, 15:12.

23. Weigel PA, Hockenberry JM, Bentler SE, Kaskie B, Wolinsky FD: Chiropractic episodes and the co-occurrence of chiropractic and health services use among older Medicare beneficiaries. J Manipulative Physiol Ther 2012, 35:168-175.

24. Weigel P, Hockenberry JM, Bentler SE, Obrizan M, Kaskie B, Jones MP, Ohsfeldt RL, Rosenthal GE, Miller J, Julian C: A longitudinal study of chiropractic use among older adults in the United States. Chiropr Osteopat 2010, 18:34.

25. Foster DF, Phillips RS, Hamel MB, Eisenberg DM: Alternative medicine use in older Americans. J Amer Geriatr Soc 2000, 48:1560-1565.

26. Ness J, Cirillo DJ, Weir DR, Nisly NL, Wallace RB: Use of complementary medicine in older Americans: results from the Health and Retirement Study. Gerontologist 2005, 45:516-524.

27. Hawk C, Long CR, Boulanger KT, Morschhauser E, Fuhr AW: Chiropractic care for patients aged 55 years and older: report from a practice-based research program. J Am Geriatr Soc 2000, 48:534-545.

28. Greene BR, Smith M, Allareddy V, Haas M: Referral patterns and attitudes of primary care physicians towards chiropractors. BMC Complement Altern Med 2006, 6:5.

29. Greene BR, Smith M, Haas M, Allareddy V: How often are physicians and chiropractors provided with patient information when accepting referrals? J Ambul Care Manage 2007, 30:344-346.

30. Smith M, Greene BR, Haas M, Allareddy V: Intra-professional and interprofessional referral patterns of chiropractors. Chiropr Osteopat 2006, 14:12.

31. Bayliss EA, Edwards AE, Steiner JF, Main DS: Processes of care desired by elderly patients with multimorbidities. Fam Pract 2008, 25:287-293.

32. Taylor A, Price K, Gill T, Adams R, Pilkington R, Carrangis N, Shi Z, Wilson D: Multimorbidity-not just an older person's issue. Results from an Australian biomedical study. BMC Public Health 2010, 10:718

33. American Geriatrics Society Expert Panel on the Care of Older Adults with Multimorbidity: Guiding principles for the care of older adults with multimorbidity: an approach for clinicians. J Amer Geriatr Soc 2012, 60:E1-E25.

34. van den Bussche $H$, Koller D, Kolonko T, Hansen $H$, Wegscheider $K$, Glaeske G, von Leitner EC, Schafer I, Schon G: Which chronic diseases and disease combinations are specific to multimorbidity in the elderly? Results of a claims data based cross-sectional study in Germany. BMC Public Health 2011, 11:101.

35. Marengoni A, Rizzuto D, Wang HX, Winblad B, Fratiglioni L: Patterns of chronic multimorbidity in the elderly population. J Amer Geriatr Soc 2009, 57:225-230

36. Marengoni A, Angleman S, Fratiglioni L: Prevalence of disability according to multimorbidity and disease clustering: a population-based study. J Comorbidity 2011, 1:11-18.

37. Haider SI, Johnell K, Weitoft GR, Thorslund M, Fastbom J: The influence of educational level on polypharmacy and inappropriate drug use: a register-based study of more than 600,000 older people. J Amer Geriatr Soc 2009, 57:62-69.

38. Qato DM, Alexander GC, Conti RM, Johnson M, Schumm P, Lindau ST: Use of prescription and over-the-counter medications and dietary supplements among older adults in the United States. JAMA 2008, 300:2867-2878.

39. Green JL, Hawley JN, Rask KJ: Is the number of prescribing physicians an independent risk factor for adverse drug events in an elderly outpatient population? Amer j geriatr pharmacotherapy 2007, 5:31-39.

40. Hush JM, Refshauge K, Sullivan G, De Souza L, Maher CG, McAuley JH: Recovery: what does this mean to patients with low back pain? Arthritis Rheum 2009, 61:124-131.

41. Liddle SD, Baxter GD, Gracey JH: Chronic low back pain: patients' experiences, opinions and expectations for clinical management. Disabil Rehabil 2007, 29:1899-1909.

42. Hsu C, Cherkin DC, Hoffmeyer S, Sherman KJ, Phillips WR: Patient and clinician openness to including a broader range of healing options in primary care. Ann Fam Med 2011, 9:447-453.

43. Noel PH, Chris Frueh B, Larme AC, Pugh JA: Collaborative care needs and preferences of primary care patients with multimorbidity. Health Expect 2005, 8:54-63.

44. Slade SC, Molloy E, Keating JL: 'Listen to me, tell me': a qualitative study of partnership in care for people with non-specific chronic low back pain. Clin Rehabil 2009, 23:270-280.

45. Matthias MS, Bair MJ, Nyland KA, Huffman MA, Stubbs DL, Damush TM, Kroenke K: Self-management support and communication from nurse care managers compared with primary care physicians: a focus group 
study of patients with chronic musculoskeletal pain. Pain Manag Nurs 2010, 11:26-34.

46. Bair MJ, Matthias MS, Nyland KA, Huffman MA, Stubbs DL, Kroenke K, Damush TM: Barriers and facilitators to chronic pain self-management: a qualitative study of primary care patients with comorbid musculoskeletal pain and depression. Pain Med 2009, 10:1280-1290.

47. Ong BN, Hooper H: Involving users in low back pain research. Health Expect 2003, 6:332-341.

48. Goertz C, Salsbury S, Vining R, Long C, Andresen A, Jones M, Lyons K, Hondras M, Killinger L, Wolinsky F, Wallace R: Collaborative Care for Older Adults with low back pain by family medicine physicians and doctors of chiropractic (COCOA): study protocol for a randomized controlled trial. Trials 2013, 14:18.

49. Krueger RA, Casey MA: Focus groups: a practical guide for applied research. 4th edition. Thousand Oaks, CA: Sage Publications; 2009.

50. Loeb S, Penrod J, Hupcey J: Focus groups and older adults: tactics for success. J Gerontol Nurs 2006, 32:32.

51. Hsiao AF, Ryan GW, Hays RD, Coulter ID, Andersen RM, Wenger NS: Variations in provider conceptions of integrative medicine. Soc Sci Med 2006, 62:2973-2987

52. Franzel B, Schwiegershausen $M$, Heusser $P$, Berger B: How to locate and appraise qualitative research in complementary and alternative medicine. BMC Complement Altern Med 2013, 13:125.

53. Cohen DJ, Crabtree BF: Evaluative criteria for qualitative research in health care: controversies and recommendations. Ann Fam Med 2008, 6:331-339.

54. Crabtree BF, Miller WL: Doing qualitative research. 2nd edition. Thousand Oaks, CA: Sage Publications, Inc:; 1999

55. Sommers LS, Marton Kl, Barbaccia JC, Randolph J: Physician, nurse, and social worker collaboration in primary care for chronically ill seniors. Arch Intern Med 1825, 2000:160

56. Gallo JJ, Zubritsky C, Maxwell J, Nazar M, Bogner HR, Quijano LM, Syropoulos HJ, Cheal KL, Chen H, Sanchez H, Dodson J, Levkoff SE: The Prism-E Investigators: primary care clinicians evaluate integrated and referral models of behavioral health care for older adults: results from a multisite effectiveness trial (PRISM-E). Ann Fam Med 2004, 2:305-309.

57. Boon HS, Mior SA, Barnsley J, Ashbury FD, Haig R: The difference between integration and collaboration in patient care: results from key informant interviews working in multiprofessional health care teams. J Manipulative Physiol Ther 2009, 32:715-722

58. Boon $\mathrm{H}$, Verhoef $M, \mathrm{O}^{\prime}$ Hara $D$, Findlay B: From parallel practice to integrative health care: a conceptual framework. BMC Health Serv Res 2004, 4:15.

59. Teh CF, Karp JF, Kleinman A, Reynolds CF III, Weiner DK, Cleary PD: Older people's experiences of patient-centered treatment for chronic pain: a qualitative study. Pain Med 2009, 10:521-530.

60. Hudon C, St-Cyr Tribble D, Bravo G, Hogg W, Lambert M, Poitras ME: Family physician enabling attitudes: a qualitative study of patient perceptions. BMC Fam Pract 2013, 14:8.

61. Hsu C, Phillips WR, Sherman KJ, Hawkes R, Cherkin DC: Healing in primary care: a vision shared by patients, physicians, nurses, and clinical staff. Ann Fam Med 2008, 6:307-314.

62. Farin $\mathrm{E}, \mathrm{Gramm} \mathrm{L}$, Schmidt E: The patient-physician relationship in patients with chronic low back pain as a predictor of outcomes after rehabilitation. J Behav Med 2013, 36:246-258.

63. Gulbrandsen P, Madsen HB, Benth JS, Laerum E: Health care providers communicate less well with patients with chronic low back pain: a study of encounters at a back pain clinic in Denmark. Pain 2010, 150:458-461.

64. Cayea D, Perera S, Weiner DK: Chronic low back pain in older adults: what physicians know, what they think they know, and what they should be taught. J Amer Geriatr Soc 2006, 54:1772-1777

65. Sandefur R, Febbo TA, Rupert RL: Assessment of knowledge of primary care activities in a sample of medical and chiropractic students. J Manipulative Physiol Ther 2005, 28:336-344.

66. Scott JG, Cohen D, DiCicco-Bloom B, Miller WL, Stange KC, Crabtree BF Understanding healing relationships in primary care. Ann Fam Med 2008, 6:315-322.

67. Kelley AS, Back AL, Arnold RM, Goldberg GR, Lim BB, Litrivis E, Smith CB, O'Neill LB: Geritalk: communication skills training for geriatric and palliative medicine fellows. J Amer Geriatr Soc 2012, 60:332-337.
68. Shelley BM, Sussman AL, Williams RL, Segal AR, Crabtree BF, behalf of the Rios Net Clinicians: They don't ask me so I don't tell them": patientclinician communication about traditional, complementary, and alternative medicine. Ann Fam Med 2009, 7:139-147.

69. Schafer L, Hsu C, Eaves E, Ritenbaugh C, Turner J, Cherkin D, Sims C, Sherman K: Complementary and alternative medicine (CAM) providers' views of chronic low back pain patients' expectations of CAM therapies: a qualitative study. BMC Complement Altern Med 2012, 12:234.

70. Leach CM, Mandy A, Hankins M, Bottomley L, Cross V, Fawkes C, Fiske A, Moore A: Patients' expectations of private osteopathic care in the UK: a national survey of patients. BMC Complement Altern Med 2013, 13:122.

71. Buckalew N, Haut MW, Morrow L, Weiner D: Chronic pain is associated with brain volume loss in older adults: preliminary evidence. Pain Med 2008, 9:240-248

doi:10.1186/1472-6882-13-225

Cite this article as: Lyons et al:: Perspectives of older adults on comanagement of low back pain by doctors of chiropractic and family medicine physicians: a focus group study. BMC Complementary and Alternative Medicine 2013 13:225.

\section{Submit your next manuscript to BioMed Central and take full advantage of:}

- Convenient online submission

- Thorough peer review

- No space constraints or color figure charges

- Immediate publication on acceptance

- Inclusion in PubMed, CAS, Scopus and Google Scholar

- Research which is freely available for redistribution 